\title{
The Effect of Cardiopulmonary Bypass in Coronary Artery Bypass Surgeries (On-Pump versus Off-Pump) on Erectile Function and Endothelium-Derived Nitric Oxide Levels
}

\author{
Onder Canguven, Selami Albayrak, Ahmet Selimoglu, Muhsin Balaban, Ahmet Sasmazel, \\ Ayse Baysal \\ Clinic of Urology II (OC, SA, AS, MB), Kartal Teaching and Research Hospital; Department of \\ Cardiac Surgery (AS) and Anesthesiology (AB), Kartal Kosuyolu Heart and Research Center, Is- \\ tanbul, Turkey
}

\begin{abstract}
Purpose: To investigate the effects of on-pump and off-pump coronary artery bypass grafting (CABG) on the erectile function and endothelium-derived nitric oxide (eNO) levels.

Materials and Methods: Twenty-eight consecutive patients were randomized into two groups depending on use of cardiopulmonary bypass in CABG surgery. The erectile function was evaluated by using the IIEF-5 questionnaire. The plasma eNO levels were determined at baseline and after reactive hyperemia before and after surgery. Blood was collected in one minute after cuff deflation from the radial artery on the same side.

Results: After CABG surgery the mean IIEF-5 score increased insignificantly over baseline from 14.8 to $15.8(\mathrm{p}=0.29)$ and 12.4 to $14.3(\mathrm{p}=0.11)$ after on-pump and off-pump CABG surgeries, respectively. The baseline plasma NO levels before surgery were $18.16 \pm 7.63 \mathrm{nmol} / \mathrm{L}$ in on-pump and $21.76 \pm 11.08 \mathrm{nmol} / \mathrm{L}$ in off-pump CABG. After reactive hyperemia the plasma NO levels were $22.14 \pm 10.52 \mathrm{nmol} / \mathrm{L}$ in on-pump and $21.49 \pm 9.13 \mathrm{nmol} / \mathrm{L}$ in off-pump CABG before the surgery. The difference in the plasma NO levels before surgery was not significant $(p=0.51)$. Two hours after surgery, the difference of the plasma NO levels at baseline $(24.44 \pm 12.31$ on-pump and $20.58 \pm 6.74 \mathrm{nmol} / \mathrm{L}$ off-pump $\mathrm{CABG})$ and after reactive hyperemia $(35.55 \pm 23.54 \mathrm{nmol} / \mathrm{L}$ on-pump and $23.00 \pm 15.40 \mathrm{nmol} / \mathrm{L}$ off-pump CABG) were not significantly different from each other $(\mathrm{p}=0.11)$.

Conclusions: Patients who had on-pump or off-pump CABG surgeries had higher IIEF-5 scores. Nevertheless, the improvement was insignificant in both groups. Meanwhile, on-pump or off-pump CABG surgeries did not have significant effect on plasma eNO levels.
\end{abstract}

Key words: coronary artery bypass; Blood Vessel Prosthesis; Erectile Dysfunction

Int Braz J Urol. 2011; 37: 733-738

\section{INTRODUCTION}

Erectile dysfunction (ED) is defined as the inability to achieve or maintain an erection sufficient for satisfactory sexual performance. ED is a vascular disorder and all men with ED should be considered at risk of cardiovascular disease until proven otherwise (1). Endothelial dysfunction is a key variable in the pathogenesis of atherosclerosis and its complica- tions, including ED. Coronary artery bypass grafting $(\mathrm{CABG})$ is mainly performed for patients who cannot be treated medically or by stent placement. In the last decade, off-pump choice is successfully performed by cardiac surgeons. CABG surgery with cardiopulmonary bypass (CPB) may have adverse effects on endothelial functions. CPB reduces the ability of endothelium to synthesize and release of plasma nitric oxide (NO) and this leads to increased 
risk of the postoperative complications (2). Quality of life and clinical morbidity after off-pump versus on-pump CABG were investigated in assorted articles (3-5). However, there are limited number of studies published the effect of different CABG types on erectile function.

\begin{abstract}
Aims
The aim of this study is to compare the effects of $\mathrm{CPB}$ on erectile function and the endothelium-derived NO (eNO) levels in on-pump and offpump CABG surgeries.
\end{abstract}

\section{Methods}

\section{Study Protocol}

Twenty-eight male patients with coronary artery disease (CAD) from September 2008 to October 2009 were prospectively enrolled in the study depending on the use of CPB in CABG or not. The inclusion criteria included all patients between 45 to 75 years of age, NYHA Class I-II, and CAD confirmed by angiographic study. The exclusion criteria included diabetes mellitus, renal or hepatic impairment (blood creatinine $>1.5 \mathrm{mg} / \mathrm{dL}$, blood aspartate aminotransferase (AST), blood alanine aminotransferase (ALT) levels higher than two fold of normal values) congestive heart failure, active inflammatory diseases, or a history of myocardial infarction in the past 6 months. The reasons for exclusion criteria are mainly related to the other comorbiditiesthat are associated with endothelial dysfunctions. The comorbidities have been documented to be associated with impaired response to flow mediated dilatation (FMD). These include elevated sympathetic activation (congestive heart failure), diabetes mellitus, and patients with renal or hepatic dysfunctions (6). Pre- and post-operative uses of all medications were recorded.

\section{Evaluation of Erectile Function}

The erectile function was evaluated using the IIEF-5 questionnaire (7) by one examiner who was blinded to treatment groups. Patients were stratified by baseline (preoperative) and six months after surgery, the erectile function was revaluated according to the same preoperative measures. IIEF- 5 scores were measured ED severity using IIEF- 5 scores of 22-25 (no ED) and $\leq 21$ (mild to severe ED) (7).

\section{Evaluation of plasma NO}

Blood samples for plasma NO were drawn a total of four times and in the following sequence: in the surgical room before start of the surgery prior to the reactive hyperemia procedure (basal level), after the reactive hyperemia procedure two hours after operation, and before and after reactive hyperemia procedures. The measurement of plasma NO level was based on the method introduced for reactive hyperemia $(8,9)$. A pressure cuff was placed at the brachial artery and inflated up to $250 \mathrm{mmHg}$ for 5 minutes, and it was subsequently deflated. This maneuver causes an increase in sheer stress exerted by the flow of blood over the surface of the endothelium in the brachial artery in the forearm circulation $(10,11)$. The arterial blood sample was withdrawn from the radial artery catheter on the same side in 1 minute after the deflation of the cuff for the measurement of the eNO. NO-derived end products (NO2, NO3) were measured by triiodine/ozone-based chemiluminescence assay, described elsewhere (12).

\section{Operative procedure}

Both groups underwent sternotomy procedure. In the off-pump group, all patients underwent $\mathrm{CABG}$ without $\mathrm{CPB}$. In this group patients were kept normothermic, heparin at a dose $300 \mathrm{U} / \mathrm{kg}$ was given intravenously and was reversed with protamine at a dose of $0.5 \mathrm{mg} / 300$ units. In on-pump group, CABG with $\mathrm{CPB}$ was performed under hypothermia. Heparin was administered at a dose of $300 \mathrm{U} /$ $\mathrm{kg}$ and it was reversed with protamine of $1 \mathrm{mg} / 300$ units of heparin. Induction and maintenance of anesthesia were similar for all patients and it includes administration of intravenous weight-related doses of fentanyl, midazolam, and pancuronium bromide. Central venous catheterization and radial artery cannula insertion were completed before induction of anesthesia.

\section{Statistical analysis}

Statistical analysis SPSS (Chicago, IL, USA) for Windows 15.0 statistics package program was used for statistical analysis of the data. A Student's $t$-test for paired samples was used for variables with normal distribution. Independent sample t test, $\chi^{2}$ test, Pearson correlation, and linear regression tests were 
done. The data were expressed as mean \pm standard deviation and the categorical variables as percentages. $\mathrm{P}<0.05$ was considered statistically significant.

The present clinical study was carried out in an academic institution and was approved by the Institutional Ethical Review Board. All subjects volunteered to participate in this study and gave informed consent after the objectives and method of the study had been explained. All patients had to anticipate having the same female sexual partner (vaginal intercourse was a required study activity) throughout the study for consistency in recording responses to efficacy questionnaires.

\section{Main Outcome Measures}

IIEF-5 scores were used for assessment of erectile function of the CAD patients before and after CABG surgeries. The measurement of plasma NO level was used in order to assess change in endothelial function.

\section{RESULTS}

Demographic characteristics of on-pump and off-pump groups were shown in Table-1. Based on the IIEF-5 scores, ED was present in 24 of the total 28 patients selected for the study. The degree of ED was determined as mild, mild to medium, medium and severe in 21.4, 35.7, 14.3 and $14.3 \%$ of patients, respectively. In four (14.3\%) patients, there was no ED. The mean IIEF-5 score increased insignificantly over baseline from 14.9 to $15.8(\mathrm{p}=$ $0.29)$ and 12.4 to $14.3(\mathrm{p}=0.11)$ after on-pump and off-pump CABG surgeries, respectively. Change in IIEF-5 scores was also statistically insignificant between two groups $(p=0.46)$. Comparison of IIEF-5 between on-pump and off-pump patients after surgery was shown in Table-2.

Baseline NO levels in on-pump were 18.16 $\pm 7.63 \mathrm{nmol} / \mathrm{L}$, and in off-pump they were $21.76 \pm$ $11.08 \mathrm{nmol} / \mathrm{L}(\mathrm{p}=0.64)$. Pre-operatively, after reactive hyperemia, the plasma NO levels were $22.14 \pm$ $10.52 \mathrm{nmol} / \mathrm{L}$ in on-pump and $21.49 \pm 9.13$ in offpump $(\mathrm{p}=0.96)$. Two hours after the $\mathrm{CPB}$, in both groups, baseline NO levels were $24.44 \pm 12.31$ in on-pump and $20.58 \pm 6.74 \mathrm{nmol} / \mathrm{L}$ in off-pump ( $\mathrm{p}=$ $0.66)$. The difference in the plasma NO levels in onpump $(3.98 \pm 12.29)$ and off-pump $(-1.62 \pm 16.40)$ groups before surgery was not significant $(\mathrm{p}=0.51)$.

Baseline NO level in patients without ED (n $=4$ ) was $15.45 \pm 1.46 \mathrm{nmol} / \mathrm{L}$. Pre-operatively, after reactive hyperemia, the plasma NO levels was 19.46

Table 1 - Demographic characteristics of on-pump and off-pump CABG.

\begin{tabular}{lccc}
\hline & $\begin{array}{c}\text { On-pump } \\
(\mathbf{m e a n} \pm \mathbf{S D})(\mathbf{n}=\mathbf{1 2})\end{array}$ & $\begin{array}{c}\text { Off-pump } \\
(\mathbf{m e a n} \pm \mathbf{S D})(\mathbf{n}=\mathbf{1 6})\end{array}$ & $\boldsymbol{p}^{*}$ \\
\hline Age (years) & $57.35 \pm 7.65$ & $59.30 \pm 6.72$ & 0.43 \\
Ca-channel blocker (n,\%) & $3(25)$ & $1(6.3)$ & 0.19 \\
Nitroglycerine (n,\%) & $10(83.3)$ & $8(50)$ & 0.19 \\
ACE-inhibitor (n,\%) & $9(75)$ & $4(25)$ & 0.06 \\
Beta-blocker use (n,\%) & $12(100)$ & $7(43.8)$ & $0.01^{*}$ \\
Myocardial infarction (n,\%) & $7(58.3)$ & $8(50)$ & 0.53 \\
Hypertension (n,\%) & $8(66.6)$ & $10(62.5)$ & 0.65 \\
Lipid-lowering statin use (n,\%) & $12(100)$ & $16(100)$ & 0.73 \\
Smoker (n,\%) & $10(83.3)$ & $7(43.8)$ & 0.08 \\
Total cholesterol (mg/dL) & $194.4 \pm 28.2$ & $157.7 \pm 31.2$ & 0.35 \\
HDL cholesterol (mg/dL) & $36.2 \pm 11.5$ & $39.7 \pm 16.3$ & 0.27 \\
\hline
\end{tabular}

*: $p<0.05$ statistically significant.

SD: Standard deviation 
Table 2 - Comparison between on-pump and off-pump patients.

\begin{tabular}{|c|c|c|c|}
\hline & $\begin{array}{c}\text { On-pump patients } \\
(\mathrm{n}=12)\end{array}$ & $\begin{array}{c}\text { Off-pump patients } \\
(n=16)\end{array}$ & $\begin{array}{l}\text { All patients } \\
(n=28)\end{array}$ \\
\hline \multicolumn{4}{|l|}{ IIEF-5 results before surgery } \\
\hline Normal & $2(16.6 \%)$ & $2(12.5 \%)$ & $4(14.3 \%)$ \\
\hline Mild ED (17-21) & $1(8.3 \%)$ & $1(6.3 \%)$ & $2(7.1 \%)$ \\
\hline Mild-moderate ED (12-16) & $2(16.6 \%)$ & $3(18.8 \%)$ & $5(17.9 \%)$ \\
\hline Moderate ED (8-11) & $6(50.0 \%)$ & $7(43.8 \%)$ & $13(46.4 \%)$ \\
\hline Severe ED (5-7) & $1(8.3 \%)$ & $3(18.8 \%)$ & $4(14.3 \%)$ \\
\hline $\mathrm{IIEF}-5$ mean $\pm \mathrm{SD}$ & $14.9 \pm 6.9$ & $12.4 \pm 7.1$ & \\
\hline \multicolumn{4}{|l|}{ IIEF-5 results and change after surgery } \\
\hline $\mathrm{IIEF}-5$ mean $\pm \mathrm{SD}$ & $15.8 \pm 5.3$ & $14.3 \pm 8.4$ & \\
\hline No IIEF-5 change & $7(58.3 \%)$ & $8(50.0 \%)$ & $15(53.6 \%)$ \\
\hline Increased IIEF-5 & $5(41.6 \%)$ & $7(43.8 \%)$ & $12(42.9 \%)$ \\
\hline Decreased IIEF-5 & - & $1(6.3 \%)$ & $1(3.6 \%)$ \\
\hline
\end{tabular}

$\pm 1.31 \mathrm{nmol} / \mathrm{L}$. Two hours after the CPB baseline NO levels was $13.66 \pm 6.15 \mathrm{nmol} / \mathrm{L}$.

After reactive hyperemia, the NO levels were found as $35.55 \pm 23.54$ and $23.00 \pm 15.40$ $\mathrm{nmol} / \mathrm{L}$ in on-pump and off-pump, respectively. Two hours after surgery, the difference of the plasma NO levels in on-pump $(11.11 \pm 22.02)$ and off-pump $(2.42 \pm 18.20)$ groups were not significantly different from each other $(\mathrm{p}=0.11)$.

Pearson correlation analysis of change in preoperative and postoperative plasma NO levels and IIEF-5 scores of ED patients before and 3 months after the surgery were also not significant $(r=-0.07 ; p$ $=0.84$ ). Pearson correlation analysis of preoperative and postoperative plasma NO levels and parameters that include; preoperative beta-blocker use, calcium channel blocker use, angiotensin converting enzyme inhibitors, operation time, use of CPB were done and the only relation was found with preoperative nitroglycerine use $(r=0.51, p=0.001)$.

\section{DISCUSSION}

The present study demonstrates that the patients, who were performed on-pump or off-pump CABG surgery, had similar change in IIEF-5 scores.
ED which was based on IIEF-5 scores was found in $24(85.7 \%)$ study group patients. Fifty percent $(12 / 24)$ of the patients with ED had an insignificant increase in IIEF-5 scores. Although the number of our ED patients was higher than in the previous studies which investigated cardiac patients $(13,14)$, it was found similar in patients who were candidate for CABG (15).

Outcomes of on-pump versus off-pump CABG surgery were examined in various studies on different topics $(3,4,16)$. To assess midterm quality of life after off-pump CABG with that after on-pump CABG procedure, Immer et al. compared an age- and sex-matched standard population (3). Immer et al. demonstrated that the use of CPB allows CABG surgery to be performed with excellent results without impairment in neurocognitive outcome and quality of life in low-risk patients (3). Van Dijk et al. have recently published a randomized trial referring to the data of 281 patients looking at cognitive outcome and cardiac outcomes 5 years after on- or off-pump CABG surgery (16). They found that the avoiding the use of CPB had no effect on five-year cognitive or cardiac outcomes (16). In a meta- analysis study, Marasco et al. evaluated eight prospective randomized controlled trials to assess neurocognitive out- 
comes after off-pump versus on-pump CABG (17). Marasco et al. concluded that there is no clinically relevant difference between two groups either early or late after surgery (17). According to the studies evaluating neurocognitive outcome, there was also no difference between on- or off-pump CABG surgery groups $(3,16,17)$. In a large series during the 10-year follow-up, Puskas et al. found that on-pump and off-pump of CABG result in similar survival, regardless of gender (18).

Penile erection is a neurologically driven hemodynamic action. Erection is initiated by NO, a potent vasodilator, released from the nerve endings. Further production of NO depends on increased blood flow which is also known as shear stress (19). In most vascular beds, the NO is released by a stimulus that increases the shear stress over the endothelium. Shear stress over the brachial artery has been reported to induce activation of eNOS in the endothelium. Rassaf and his colleagues showed that up to 72 to $90 \%$ of circulating plasma NO is derived from eNOS activity (11).

Although it is well established that cardiovascular risk factors are associated with $\mathrm{ED}$, once it is present there is mixed information on whether treating the risk factors will treat the ED (13). Recently, Mohamed et al. investigated the difference between the on pump and off-pump CABG surgery on the sexual function (15). The study design included subjective (IIEF-5 score) and objective (penile duplex ultrasonography) findings related to erectile function (15). The number of patients who reported post-operative improvement of their IIEF-5 score was found significantly higher in off-pump group. Nevertheless, there was no significant change in the duplex ultrasound data (peak systolic, end-diastolic velocities, and resistance index) after surgery between both groups (15). Although Mohammed et al. concluded that type of surgery can be considered a predictive factor of sexual function following $\mathrm{CAB}$ surgery, it was not clearly explained how it affects penile tissue without any change in vascular bed. Besides, previous studies demonstrated that NOmediated erectile function fundamentally involves both nNOS and eNOS locally, whereby the former initiates the erectile response and the latter facilitates full erection (19).
In our study, we investigated whether CPBinduced transient pulmonary endothelial dysfunction result in decreased NO release that contributes to post-operative change in erectile function. Although twelve patients had improved IIEF-5 scores, this increase was found insignificant. We also demonstrated that there was no significant relation between postoperative plasma NO levels after reactive hyperemia following on and off-pump CABG. The current study implied that pre-operative nitroglycerine use was associated with increased plasma levels of NO after the on or off-pump CABG.

Limitations of our study are the relatively small number of patients, the lack of long-term follow-up data. A better study design for simultaneous evaluation of FMD and plasma NO levels is warranted for further studies.

\section{CONCLUSIONS}

This study demonstrates that in on- and offpump CABG surgeries the IIEF-5 score and plasma NO levels did not reveal any significant difference in the early postoperative period.

\section{CONFLICT OF INTEREST}

None declared.

\section{REFERENCES}

1. Montorsi P, Ravagnani PM, Galli S, Salonia A, Briganti A, Werba JP, et al.: Association between erectile dysfunction and coronary artery disease: Matching the right target with the right test in the right patient. Eur Urol. 2006; 50: 721-31.

2. Beghetti M, Silkoff PE, Caramori M, Holtby HM, Slutsky AS, Adatia I: Decreased exhaled nitric oxide may be a marker of cardiopulmonary bypass-induced injury. Ann Thorac Surg. 1998; 66: 532-4.

3. Immer FF, Berdat PA, Immer-Bansi AS, Eckstein FS, Müller S, Saner H, et al.: Benefit to quality of life after off-pump versus on-pump coronary bypass surgery. Ann Thorac Surg. 2003; 76: 27-31.

4. Ivanov J, Borger MA, Tu JV, Rao V, David TE: Midterm outcomes of off-pump versus on-pump coronary artery bypass graft surgery. Can J Cardiol. 2008; 24: 279-84. 
5. Lee JD, Lee SJ, Tsushima WT, Yamauchi H, Lau WT, Popper J, et al.: Benefits of off-pump bypass on neurologic and clinical morbidity: a prospective randomized trial. Ann Thorac Surg. 2003; 76: 18-25; discussion 25-6.

6. Kuvin JT, Patel AR, Sliney KA, Pandian NG, Rand WM, Udelson JE, et al.: Peripheral vascular endothelial function testing as a noninvasive indicator of coronary artery disease. J Am Coll Cardiol. 2001; 38: 1843-9.

7. Rosen RC, Cappelleri JC, Smith MD, Lipsky J, Peña BM: Development and evaluation of an abridged, 5 -item version of the International Index of Erectile Function (IIEF-5) as a diagnostic tool for erectile dysfunction. Int J Impot Res. 1999; 11: 319-26.

8. Wassmann S, Ribaudo N, Faul A, Laufs U, Böhm M, Nickenig G: Effect of atorvastatin $80 \mathrm{mg}$ on endothelial cell function (forearm blood flow) in patients with pretreatment serum low-density lipoprotein cholesterol levels $<130 \mathrm{mg} / \mathrm{dl}$. Am J Cardiol. 2004; 93: 84-8.

9. Masumoto A, Hirooka Y, Hironaga K, Eshima K, Setoguchi S, Egashira K, et al.: Effect of pravastatin on endothelial function in patients with coronary artery disease (cholesterol-independent effect of pravastatin). Am J Cardiol. 2001; 88: 1291-4.

10. Corretti MC, Anderson TJ, Benjamin EJ, Celermajer D, Charbonneau F, Creager MA, et al.: Guidelines for the ultrasound assessment of endothelial-dependent flow-mediated vasodilation of the brachial artery: a report of the International Brachial Artery Reactivity Task Force. J Am Coll Cardiol. 2002; 39: 257-65. Erratum in: J Am Coll Cardiol 2002; 39: 1082.

11. Rassaf T, Kleinbongard P, Preik M, Dejam A, Gharini $\mathrm{P}$, Lauer T, et al.: Plasma nitrosothiols contribute to the systemic vasodilator effects of intravenously applied NO: experimental and clinical Study on the fate of NO in human blood. Circ Res. 2002; 91: 470-7.

12. Dejam A, Hunter CJ, Pelletier MM, Hsu LL, Machado RF, Shiva S, et al.: Erythrocytes are the major intravascular storage sites of nitrite in human blood. Blood. 2005; 106: 734-9.

13. Kloner RA, Mullin SH, Shook T, Matthews R, Mayeda G, Burstein S, et al.: Erectile dysfunction in the cardiac patient: how common and should we treat? J Urol. 2003; 170: S46-50; discussion S50.
14. Chew KK, Finn J, Stuckey B, Gibson N, Sanfilippo F, Bremner A, et al.: Erectile dysfunction as a predictor for subsequent atherosclerotic cardiovascular events: findings from a linked-data study. J Sex Med. 2010; 7: 192-202.

15. Mohamed OA, Bennett CJ, Roaiah MF, Helmy T, Mahran A, Hamed HA: The impact of on-pump coronary artery bypass surgery vs. off-pump coronary artery bypass surgery on sexual function. J Sex Med. 2009; 6: 1081-9.

16. van Dijk D, Spoor M, Hijman R, Nathoe HM, Borst C, Jansen EW, et al.: Cognitive and cardiac outcomes 5 years after off-pump vs on-pump coronary artery bypass graft surgery. JAMA. 2007; 297: 701-8.

17. Marasco SF, Sharwood LN, Abramson MJ: No improvement in neurocognitive outcomes after offpump versus on-pump coronary revascularisation: a meta-analysis. Eur J Cardiothorac Surg. 2008; 33: 961-70.

18. Puskas JD, Kilgo PD, Lattouf OM, Thourani VH, Cooper WA, Vassiliades TA, et al.: Off-pump coronary bypass provides reduced mortality and morbidity and equivalent 10 -year survival. Ann Thorac Surg. 2008; 86: 1139-46; discussion 1146.

19. Burnett AL: Novel nitric oxide signaling mechanisms regulate the erectile response. Int J Impot Res. 2004; 16(Suppl 1): S15-9.

\section{Submitted for publication:}

January 10, 2011

\section{Accepted after revision:} May 12, 2011 